ISSN 1112-9867

Available online at

http://www.jfas.info

\title{
ANALYZING THE EFFECT OF NATURE ON SOCIAL INTERACTION IN URBAN SQUARES (CASE EXAMPLES: SQUARES OF TEHRAN)
}

\author{
M. Bemanian* ${ }^{1}$, Z. Ghasemi ${ }^{2}$, H. Saremi ${ }^{3}$ and M. Sattarpour ${ }^{4}$ \\ ${ }^{1}$ Professor of Architecture, School of Art and Architecture, Tarbiat Modarres University, \\ Tehran, Iran \\ ${ }^{2} \mathrm{PhD}$ student, Department of Architecture, Department of Boroujerd, Islamic Azad \\ University, Tehran, Iran \\ ${ }^{3}$ Assistant Professor of Urban Planning, Faculty of Arts and Architecture, Tarbiat \\ Modarres University, Tehran, Iran \\ ${ }^{4} \mathrm{PhD}$ student, Department of Architecture, Department of Boroujerd, Islamic Azad \\ University, Tehran, Iran
}

Published online: 15 May 2016

\begin{abstract}
One of issues that have been considered in the urban environment is improving the quality of these spaces. Enjoying nature and its elements can play a role in promoting them; this role can be searched in the relationship between man, nature and characterization of natural effects on the built environment and their interactions with each other. Because of the importance of urban environments as one of the most important of this space and their role in the development of society, the focus is on squares and the influence of nature on social interactions and how to respond to some psychological needs of human nature is assessed.
\end{abstract}

Author Correspondence, e-mail: bemanian@modares.ac.ir doi: http://dx.doi.org/10.4314/jfas.v8i3s.244 
In this study, using descriptive-analytical study and library method it was confirmed that vitality and sociability in urban areas, have a significant impact on increasing social interaction and increasing these factors improve urban spaces. By using correlation method and questionnaire and their analysis using SPSS software it was concluded that proper use of designed natural space, has a significant impact on satisfaction, socialization, creating vitality and ultimately increase local identity and social interaction.

Keywords: Urban Space, Square, Natural Space, Vitality, Sociability, Social interaction

\section{INTRODUCTION}

The formation of human behavior is the outcome of stimulation, individual needs, abilities and perception of his environment. The urban space is a place of revelation; the meeting scene and meeting people and lack of attention to crisis and conflict cognitive behavioral patterns with functional content space.

Cities have spaces that are an expression of culture, technology and civilization in a society. Urban spaces of a society are special for the people that affect society and their mutual interaction. Identity reflects the features of any person or phenomenon (Bemanian, et al., 2010, 40). Public spaces and the face of a city can reveal the identity of the inhabitants of that city. As well as the social, cultural, artistic and economic impact of a society and takes any particular form. These types of spaces are open spaces that can be scenes of social life in many events in the city. Urban space can facilitate social relations, social structure refinement, process and field of applied social norms and social norms in other words, the field is the Live Demo (Parsi, 2002, 41).

This article is trying to show the importance of designing in the natural space in urban areas such as square and consider increasing vitality and enhancing the quality of these spaces and influence the nature of the various factors. Concepts such as satisfaction, socialization, and vitality have been raised in this study and play roles in increasing social interaction in urban squares. 


\section{METHODOLOGY}

In this study, by using descriptive-analytical study, and library method and using existing documents, the relationship of satisfaction and socialization and vitality in the growth of social interactions was assessed and by using correlation method and questionnaire and their analysis using SPSS software it was concluded that proper use of designed natural space, has a significant impact on satisfaction, socialization, creating vitality and ultimately increase local identity and social interaction. The statistical population of this study included 6 Squares in Tehran that has been completed by specialists' questionnaire.

\section{REVIEW OF LITERATURE}

Given the importance of the natural environment and urban spaces, several studies have been conducted on these two issues separately. In the meantime, we can mention theorists such as Ems Rappaport (1977), the issue of interaction between humans and the environment posed in planning and urban design, As well as theories and city guide books and right Paul Zucker (1959), City outlook Kevin Lynch (1960), Urban landscape Gordon Cullen (1961), the urban space Rob Carrier (1975), the creation of architectural theory (the role of Behavioral Sciences in Environmental Design), John Lang (1987) Analysis of urban spaces in relation to the behavior patterns of H. Bahraini (1996), Urban Design: the streets and squares Cliff Matyn (1999) design of urban space, Ali Madani Poor (2000), urban design in Iran, Jahanshah Pakzad (2005) which as a whole or case study have examined the relationship between neighborhoods and the city in public spaces.

In the area of natural space and its role in the urban area there are also numerous studies, and there are different styles in line with the friendship between an artificial environment and nature. It should be noted that little research on the relationship between natural environment as one of the most important urban spaces has been conducted. As a result this study can be used to increase the quality and pay special attention to the natural environment.

\section{SQUARE}

Human life has social nature, and the system does not exist except with the division of 
responsibilities and tasks in accordance with the laws, traditions. Public space is a "co-location space for the presentation of the reality test and exploration in the area of identity and difference and to be accepted by others" (Madanipur, 2008, 266). Human by using thinking skills come to the conclusion that the partnership and cooperation has a better life and more interest is the creation of endowments, hence the idea of public participation agreement is a natural and rational demands. Squares are perfect places for the presence and participation of citizens in public life and their interaction and have led to further understand the interaction and being together, thus improving it, promote the individual members of society and the whole society.

\section{4-1 Social interactions}

If the person does an act that is associated with the response from the other person, called to the mutual interaction is called social interaction. In this case, a social relation is established between the two people (Fielding Agbern and NimKuf, 13). Human needs are generally divided into two categories: material and spiritual nature and social interactions can be named as one of man's natural needs. Thus, interactions and social relations can be mentioned as a natural need and the means to satisfy other needs. So that man is not able to live without social relationships (RAFIPOUR, 2003). Type, quality and spatial association of urban spaces can be shaped in the form of constructive interactions of social and civic participation or to organize social capital are important in urban structure (Pourmohammadi, Kushaneh, 2013, 44). Increased vitality, environmental quality is affecting factors of social interactions. As well as in the development of socialization and social interaction lasting impact and thus improve and enhance the quality of knowledge and experience to the users.

Individuals from birth through their life form social skills, these skills have profound impact on human capabilities and activities (games, work, learn, how to fill leisure) (Aksoy, Baran, 2010, 663). Vygotsky knows social skills and cognitive development determines, so we should strengthened the social environment to improve human cognitive development and environment. In his opinion, knowledge and attitudes and values of the person in the process of interaction with others evolve (Seif, 2007, 220). Possession of a city as a platform for the continuous presence of people at different times of day is one of the characteristics of 
relationships and social interactions that are deemed to be integral.

\section{4-1-1 Sociability}

Social spaces and consequently the socialization include individuals and social groups that exchange and share with each other ideas and information. Such spaces are more than just a space, they are an experience (Hajer, Reijndorp, 2001, 11). According to Smond, using keywords such as "socialization spaces" or " Sociopetal Spaces," "gathering spaces and socialization" or "scattering spaces" represent the spatial qualities that people get together, or live apart (Smond, 1957, 26). Social spaces provide an opportunity to the users to make space for social dialogue and social interactions to occur more easily in such an environment.

\section{4-1-2 Vitality:}

Lively urban space is an urban space where the presence of a significant number of people and their diversity (in terms of age and sex) in a wide range of day when their activities occur mainly in the form of selective or social (Khestou, Saeidi Rezavani, 2010, 64). The role of urban space, i.e. space where social interaction of citizens is formed and the context of our culture will be upgraded, in our country is declining day by day. Cities and neighborhoods that act like a living organism to survive and are in need of vitality. Life and individual life is the sum of what space gives to life, people and vital presence in space (Pakzad, 2003, 98). This is the perfect background to establish social interaction, with vitality it can become more active and more majestic and further increase the sense of belonging in that space. Clearly, the necessary vitality of the people in the city's urban spaces (Khestou, Saeidi Rezavani, 2010, 64). To achieve urban life or vitality in the city, to places and situations that provide for a lovely experience (Leonard, 1998, 82). This location provides the conditions so that the people involved in them and form a better quality for social relationships.

\section{NATURAL SPACES AND SQUARES}

\section{5-1 Natural space in the past and contemporary time}

Human beings from the beginning of his life inspired by nature in various forms and this trend will continue for future generations. Man has always sought to enhance the quality in all the spaces and the natural environment shapes and different styles have always been a good way 
of solving. What in this study is considered as nature is the use of elements such as water or green space is the same spaces for gardens, including trees and shrubs in the yard. Because we are part of nature for it to become full human beings we should be in touch with nature (Andrew Brennan According to Bell, 2003, 119). Spiritual and material relationship with nature for a man is very important and this is emphasized in Islam and in different ways reflects on nature and natural phenomena. Human naturally value thinking and Islam called it as one of the most important acts of worship and places where humans are associated with it, should encouraged him and consider it to draw an infinite universe.

In the Islamic perspective, nature and proximity to the divine and innate wisdom and intuition can be achieved, in this view, many recommendations to interact with human-made environments and facilitate communication with mature imitated the traditional architecture has been building a house". The interlinking of qualities, forces and flow of different elements, circulating rhythms of light and dark skies and incessant repetition of the traditional Islamic architecture is its resonant and not only does not hide them but also makes it obvious that other revelation of God's nature is to be noted (Nasr, 2010, 69). In the past architecture utilizes the natural environment elements such as water, trees, greenery and light in semi-closed environments. The use of nature in traditional home, neighborhood centers, public spaces such as mosques, schools, caravanserais were existed.

In contemporary architecture using nature is embodied in various forms, this urban design eco-friendly furniture to the use of natural elements such as ponds and water fountains, streams, rocks and boulders, large and small, grass, trees, flowers and bush and on the field of contemporary urban, the elements with creative design and perfect world can be seen in important squares, Hidalgo Square in Mexico City, Plaza Santa Anna in Spain and Antarvasna square in Uruguay are examples of these squares.

According to Zucker, square is like psychological place where it has people social interaction in the urban landscape and at the same time, Zucker urban design and aesthetics are not only limited to procedural aspects and emphasized the social aspects and current activities in space strongly (Zucker, 1970, 6). As it was stated by human activities and no need is limited to material needs and attention to the spiritual dimension is also very important. Nature as a 
factor in human life, stay away from negative and bad influences that creates in the human psyche. Our identity is associated with nature and the most basic steps to preserve it and the importance of adherence to environmental ethics. It is not logical to recognize the benefits of direct contact with nature but not pay attention to its survival (Andrew Brennan According to Bell, 2003: 119). Fit and proper utilization of nature and natural elements have contributed to the survival and continuation of an environment and make sense of the man-made environments in the modern urban spaces. Such spaces act like a living space in the city today and it is a pause point to attend more citizens.

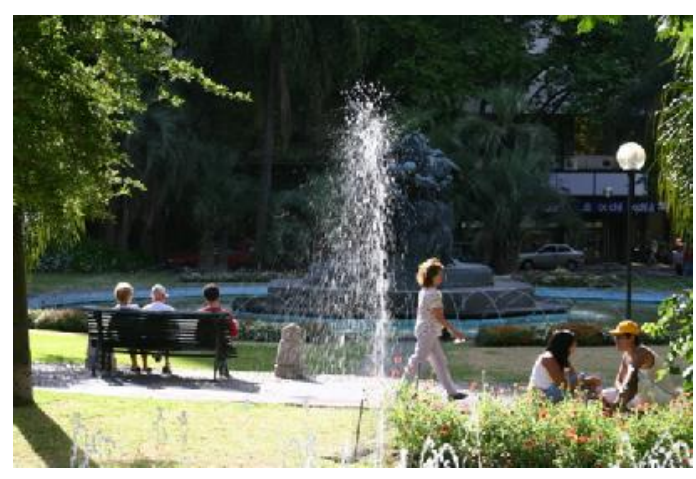

Image 1: Natural space at Antarvasna square in Uruguay http://www.pps.org

\section{5-2 Objectives of using natural space in square}

Squares are mentioned as an important urban space and the quality of the absorption and optimal utilization of valuable citizens are effective. The use of natural space in squares of modern cities, is reduced the role of nature in human life and it has various purposes and a number of them are mentioned below.

1- Nature makes the sense of belonging to a place: many contemporary thinkers found indispensable the sense of belonging to a place and to maintain harmony with nature. Theorists such as (Chermayeff) and (Alexander), mentioned the absence of nature in modern life. They described sincerely touch of man with nature unparalleled joy (Chermayeff and Alexander, 1974, 48). Natural spaces have important impact on people's feelings and their aesthetic understanding and can increase positive emotions and comfort and belongingness towards the environment. Close relationship with nature in the growth and development of mental and physical relaxation and positive 
individuals (Hafezian, 2006, 78). Creating positive feelings and a sense of peace of mind caused by users of the environment and through that understanding and sense of belonging to a place and make more comfortable living environment and society. The sense of belonging to a place where there based on a sense of place that makes your man know part of the place and based on their experience of signs, meanings and performance, character and role envisaged for places in mind and thus be respected and important place (Falahat, 2006, 60).

2- Creating a favorable environment for users: using natural spaces such as shading trees and the use of elements such as water and fountains to modify and create a pleasant space in climate of most cities is very useful. Natural spaces create a favorable environment for users in the squares and make an opportunity that many meetings and leisure during daylight hours for short-term or even a few hours can occur in these spaces.

3- Nature and its elements such as trees and water in Iranian culture was very valuable in addition to its functional aspect it has a semantic aspects. Islam also reflects the nature. Religious insight that comes from Islamic Verses recommends the operation and at the same time constructive in nature and in regard of spiritual attention knows interaction with nature and natural action than contemplation of spiritual growth source material efficiency; understand the power of God and a spirit of worship (Dai Poor, 2014, 51).

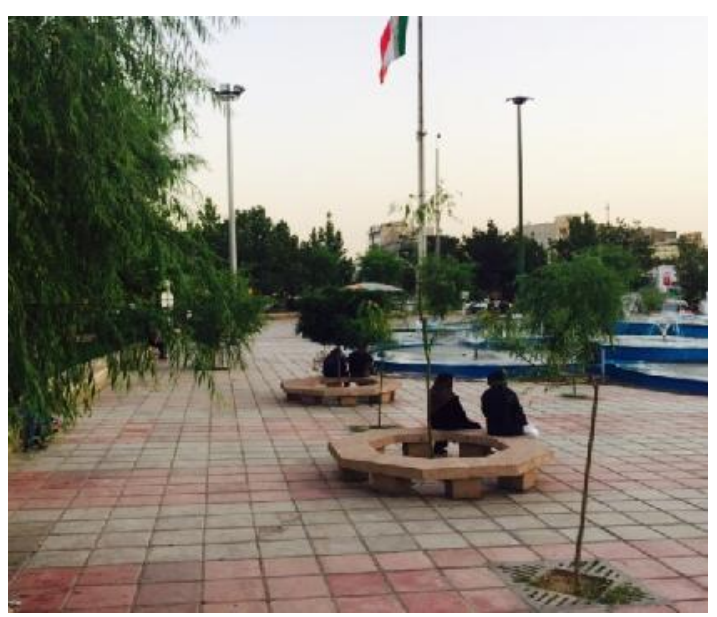

Image 2: Natural elements in square of FALAKE AVAL TEHRANPARS 


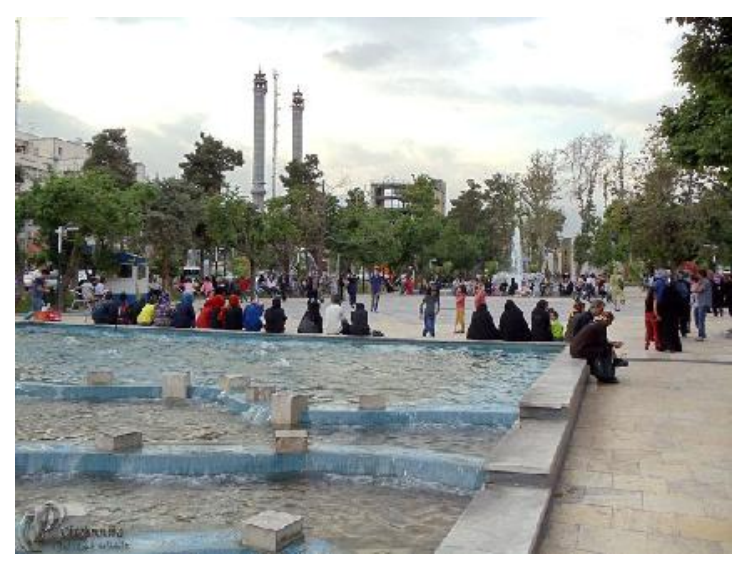

Image 3: Natural elements in HAFT HOZ square, Tehran

\section{6- DISCUSSION}

People and activities that they do in a city are like mobile factors that are effective in creating the image of a city. Creating natural spaces around the square in addition to highlight the presence of the people, makes the image and the face of the city, beautiful.

In this study 6 squares in Tehran were evaluated through a questionnaire, completed by 10 specialists in the field. The purpose of this study was to analyze the relationship as lively as in the field of urban and spatial association with the use of natural space in them. In this regard, the natural environment is considered as an independent variable to be evaluated its impact on the vitality and sociability. The study was conducted by using correlation method and questionnaire and their analysis using SPSS software.

Regression coefficients are used in the relationship between factors and the exact formula. The regression coefficients were determined from the table that is marked in the table. To determine the relationship between factors correlation table can be used. The table determines the direct or inverse relationship between the number of agents and their impact on each other. Natural environment is independent variable and community life is dependent variable. After performing the calculations it showed that the cause of nature, life and socialization had a direct relationship with each other; in other words, the natural environment and the vitality and flexibility of each affected community and given the positive correlation coefficient had direct relationship, it means the increase in natural and green space will increase these two factors (Table 1). Also vitality and sociability factors had direct relationship; in other words vitality and sociability factor affected on each other; and given the positive correlation 
coefficient it is a direct relationship, it means increasing socialization will increase vitality (Table 2).

Table 1: Extracted Regression coefficients

\begin{tabular}{|c|c|c|c|c|c|c|}
\hline \multicolumn{2}{|c|}{ coefficients } & & & \multicolumn{2}{|c|}{ Extracted } & Regression \\
\hline \multirow{2}{*}{\multicolumn{2}{|c|}{ Sample }} & \multicolumn{2}{|c|}{$\begin{array}{l}\text { Non-standard } \\
\text { Regression } \\
\text { coefficients }\end{array}$} & \multirow{2}{*}{$\begin{array}{l}\text { Standard } \\
\text { Regression } \\
\text { coefficients }\end{array}$} & \multirow{2}{*}{$\begin{array}{l}\mathrm{t} \\
\text { statistic }\end{array}$} & \multirow{2}{*}{$\begin{array}{l}\text { Significant } \\
\text { level }\end{array}$} \\
\hline & & B & $\begin{array}{l}\text { Std. } \\
\text { Error }\end{array}$ & & & \\
\hline \multirow{3}{*}{1} & Dependent & .425 & .200 & & 2.123 & .038 \\
\hline & Socialization & .451 & .087 & .527 & 5.202 & .000 \\
\hline & Vitality & .371 & .092 & .410 & 4.045 & .000 \\
\hline
\end{tabular}

Table 2: Correlational coefficient

\begin{tabular}{|c|c|c|c|c|}
\hline \multicolumn{5}{|c|}{ Correlational coefficient } \\
\hline & & & Socialization & Vitality \\
\hline \multirow[t]{6}{*}{ Spearman's rho } & \multirow[t]{3}{*}{ Socialization } & Correlational coefficient & 1.000 & $.768 * *$ \\
\hline & & Significant level & . & .000 \\
\hline & & Number & 60 & 60 \\
\hline & \multirow[t]{3}{*}{ Vitality } & Correlational coefficient & $.768 * *$ & 1.000 \\
\hline & & Significant level & .000 & . \\
\hline & & Number & 60 & 60 \\
\hline \multicolumn{3}{|c|}{ **. Correlation is significant at the 0.01 level (2-tailed). } & & \\
\hline
\end{tabular}

This test demonstrates the flexibility and vitality affected each other and according to the positive Spearman correlation coefficient $=* * 768$, this is a direct relationship; it means increasing socialization will increase vitality and vice versa (Table 2). 


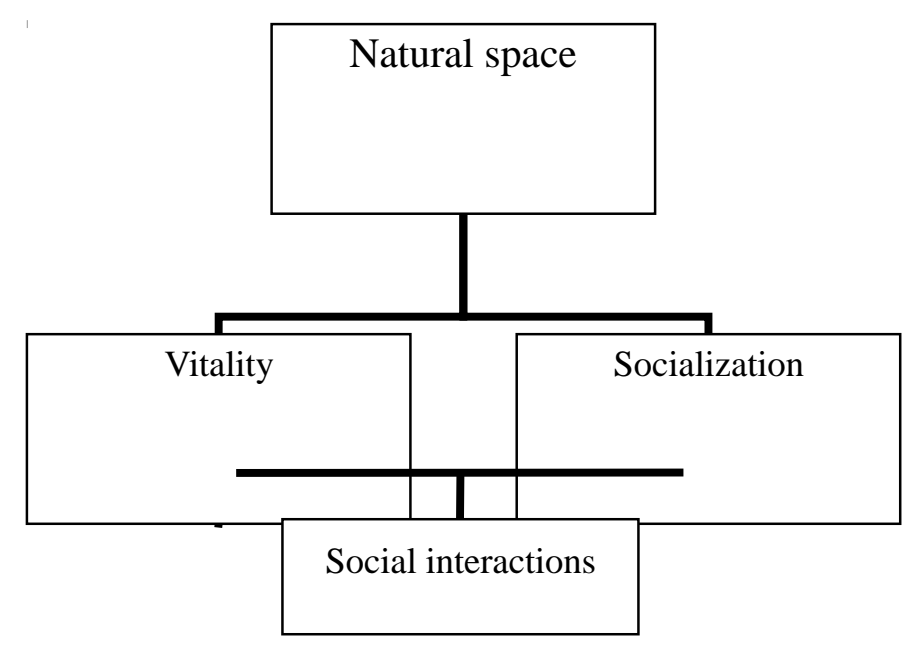

Fig.2. The relationship between natural space, sociability, vitality and social interactions

\section{CONCLUSION}

A city to approach the ideal urban has many spaces that enhance social interaction and solidarity among human beings. Architecture and urban development shall be directed to the link between people and public spaces such as squares take important step for appropriate context for social interactions. One of the most important measures to enhance the quality of the urban environment is combining this environment with the natural environment and the use of multi-tasking nature. Green spaces, water and the presence of nature with living spaces was customary in old neighborhoods from the old days and at the present time, according to the new scale commensurate with the scale of the cities.

This study shows that factors such as vitality and sociability play an important role in social interactions; each led to an increase in social interaction and thus improves the knowledge society. The use of natural space increased vitality and sociability that ultimately increase social interaction. The study also found that socialization and vitality affect each other and also has a direct relationship, and increasing one will increase the other one. Today in many 
areas of social and individual life human ignored use nature and its elements while using nature in all areas, especially urban modern spaces that little attention is paid to man's natural needs, can be fruitful.

\section{REFERENCES}

1- Bell, Simon, landscape pattern, perception and process, 2003

2- Bemanian, MR, Pourjafar, Mohammadreza, Ahmadi, Ferial, Sadeghi, Ali Reza, Reading spiritual identity and the notion of sacred architecture Shiite mosques, Shia Studies Quarterly, Issue 30, Qom, pp. 70-37, 2010

3- Parsi, HR, understanding the content of the urban space of Fine Arts, Issue 11, pp. 41-49, 2002.

4- Pakzad, Jahanshah, qualitative criteria to measure the space, Abadan, No. 39, 2003.

5- Pour-Mohammadi, MR, Kushaneh, clear analysis and evaluation of urban public spaces using TOPSIS (Case Study: Tabriz), urban and regional studies, No. XVII, page $37-52,2013$

6- Chermayeff, Serj and Alexander, Christopher, 1974, the areas of private life and public life

7- Hafezian, T. 2006. Green space, school magazine, No. 41, Tehran.

8- Khastou, Mary, Saeedi Rezvani, Navid: Factors affecting the vitality of urban spaces to create a lively urban space based on the concept of the shopping center on foot, Journal identity of the city, Issue 6, 2010, page 63-74.

9- Falahat, Mohammad Sadiq. 2006. The concept of a sense of place, and composing factors. College of Fine Arts, Issue 26, 57-66.

10- Fielding Agbern and NimKuf, Francis Mayer, 2001 Sociology Context

11-Dai pour, Zainab. 2014. The relationship of nature and increase the sense of belonging in a traditional home. Garden Quarterly Review, Issue 30, the eleventh year

12-RAFIPOUR, F, Anatomy Society: An Introduction to Sociology, Applied. Tehran: Publishing Corporation, 2003. 
13-Saif, Ali Akbar, Educational psychology (teaching and learning), Tehran, publishing aware, 2007.

14- Krohercents, Leonard, Susan and Henry Leonard, "Designing urban space and social life" 1998

15-Madanipour, Ali, Urban, public and private spaces, Farshad Nourian, processing enterprises and urban planning, Tehran, 2008.

16- Nasr, Seyed Hossein, Islamic art and spirituality. Tehran: Wisdom Publications, 2010.

17- Aksoy, pinar, Baran, Gulen (2010) Review of studies aimed at bringing social skills for children in preschool period. Procardia social and Behavioral sciences 663_669.

18-Smond H, Function as the Basis of Psychiatric Ward Design. New York. Holt Rinehart and Winston, 1957.

19-Hajer, M and Reijndorp, A; 'In Search of New Public Domain'; Rotterdam; NAi Publishers, p.11, 2001.

20-Zucker, Paul (1970), “Town and Square; From the agora to the village Green”, The MIT Press,

21- http://www.pps.org/reference/internationalsquares/

\section{How to cite this article:}

Bemanian M, Ghasemi Z, Saremi H, Sattarpour M. Analyzing the effect of nature on social interaction in urban squares (case examples: squares of tehran). J. Fundam. Appl. Sci., 2016, 8(3S), 1113-1125. 